\title{
COMMENTS ON “MULTIPLE CRITERIA DECISION MAKING (MCDM) METHODS IN ECONOMICS: AN OVERVIEW”
}

\author{
James J. H. Liou', Gwo-Hshiung Tzeng ${ }^{2}$ \\ ${ }^{1}$ Department of Industrial Engineering and Management, National Taipei University of Technology, \\ No. 1, Section 3, Chung-Hsiao East Road, Taipei, Taiwan \\ ${ }^{2}$ School of Commerce, Kainan University, No. 1, Kainan Road, Luchu, Taoyuan 338, Taiwan \\ ${ }^{2}$ Institute of Management of Technology, National Chiao Tung University, \\ 1001, Ta-Hsueh Road, Hsinchu 300, Taiwan \\ E-mails: ${ }^{1}$ jamesjhliou@gmail.com; ${ }^{2}$ ghtzeng@mail.knu.edu.tw (corresponding author)
}

Received 19 March 2012; accepted 13 October 2012

\begin{abstract}
This paper offers comments on a previously published paper, titled "Multiple criteria decision making (MCDM) methods in economics: an overview," by Zavadskas and Turskis (2011). The paper's authors made great efforts to summarize MCDM methods but may have failed to consider several important new concepts and trends in the MCDM field for solving actual problems. First, the traditional model assumes the criteria are independently and hierarchically structured; however, in reality, problems are often characterized by interdependent criteria and dimensions and may even exhibit feedback-like effects. Second, relatively good solutions from the existing alternatives are replaced by aspiration levels to fit today's competitive markets. Third, the emphasis in the field has shifted from ranking and selection when determining the most preferable approaches to performance improvement of existing methods. Fourth, information fusion techniques, including the fuzzy integral method, have been developed to aggregate the performances. Finally, the original fixed resources in multi-objective programming are divided such that both decision and objective spaces are changeable. In this paper, we add new concepts and provide comments that could be thought of as an attempt to complete the original paper.
\end{abstract}

Keywords: MCDM (Multiple Criteria Decision Making), Interdependence, Information fusion, Non-additive, Changeable space, Economics.

Reference to this paper should be made as follows: Liou, J. J. H.; Tzeng, G.-H. 2012. Comments on "Multiple criteria decision making (MCDM) methods in economics: an overview", Technological and Economic Development of Economy 18(4): 672-695.

JEL Classification: C00, C02, C18, C54, C60, C61, D70, D78, O20. 


\section{Introduction}

Zavadskas and Turskis' (2011) work, titled "Multiple criteria decision making (MCDM) methods in economics: an overview," has made a considerable contribution to the field. These researchers present a panorama of decision making methods in economics, summarizing the most important results and applications over the last five years. These authors present a thorough historical review and classify and illustrate the primary steps of MCDM methods. The authors go on to discuss several opportunities for future research. The methods illustrated were, however, mostly developed in the 1980s and 1990s but have recently been applied to new fields. We feel that important research into new methods and current trends was not adequately addressed in the paper.

For example, a new hybrid dynamic multiple-criteria decision making (HDMCDM) method for problem-solving in interdependent and feedback situations in the fields of economics and business has been proposed (Chen et al. 2011; Ho et al. 2011). For multiple-objective decision making (MODM) problems, several researchers developed a new changeable space including decision space and objective space (CDOS) method that incorporates many of the realities of a dynamic and changing environment. Tzeng and Huang (2012a) applied the De Novo method of optimization in the objective space, given constraints in the decision space, to determine the aspiration levels for all objectives (Huang, Tzeng 2007). With regard to nontraditional MCDM methods, Greco et al. (2010) developed a decision rule approach based on the dominance-based rough set theory. Deb et al. $(2002,2011)$ applied a genetic algorithm to solve MODM problems. In this paper, not only we discuss the Zavadskas and Turskis paper, but also provide more reference material for greater completeness. This supplemental material could help readers understand the complete scope of MCDM and demonstrate the benefits of MCDM in economics and business.

Fig. 1 illustrates the basic concepts of problem solving. Through either data collection or investigation of objectives, the responses and social and personal attributes of the objectives may be represented as a data set (e.g., crisp, fuzzy or rough set). These data can be further analyzed using data processing techniques (e.g., data mining, statistical/multivariate analysis, neural networks or logic reasoning) or forecasting models (e.g., regression, fuzzy regression, grey forecasting or Bayesian regression). The data could also be analyzed using MCDM. MCDM can be roughly separated into MODM (Multi-Objective Decision Making) and MADM (Multi-Attribute Decision Making) components. MODM includes goal programming (GP), multiple objective programming (MOP) and compromise solution methods. These problems can be solved using many methods including single level, fuzzy, multi-stage and dynamic methods. MADM includes structure relation methods (e.g., interpretive structural modeling (ISM), Decision Making Trial and Evaluation Laboratory (DEMATEL) or fuzzy cognitive map), weight analysis (e.g., Analytic Hierarchy Process (AHP), Analytic Network Process (ANP) or entropy measure) and performance aggregated methods (e.g., simple additive weight (SAW), Technique for Order Preference by Similarity to an Ideal Solution (TOPSIS), ELECTRE or grey relation for additive types and fuzzy integral for non-additive types). Data envelopment analysis (DEA) is a method to investigate problems with multiple 


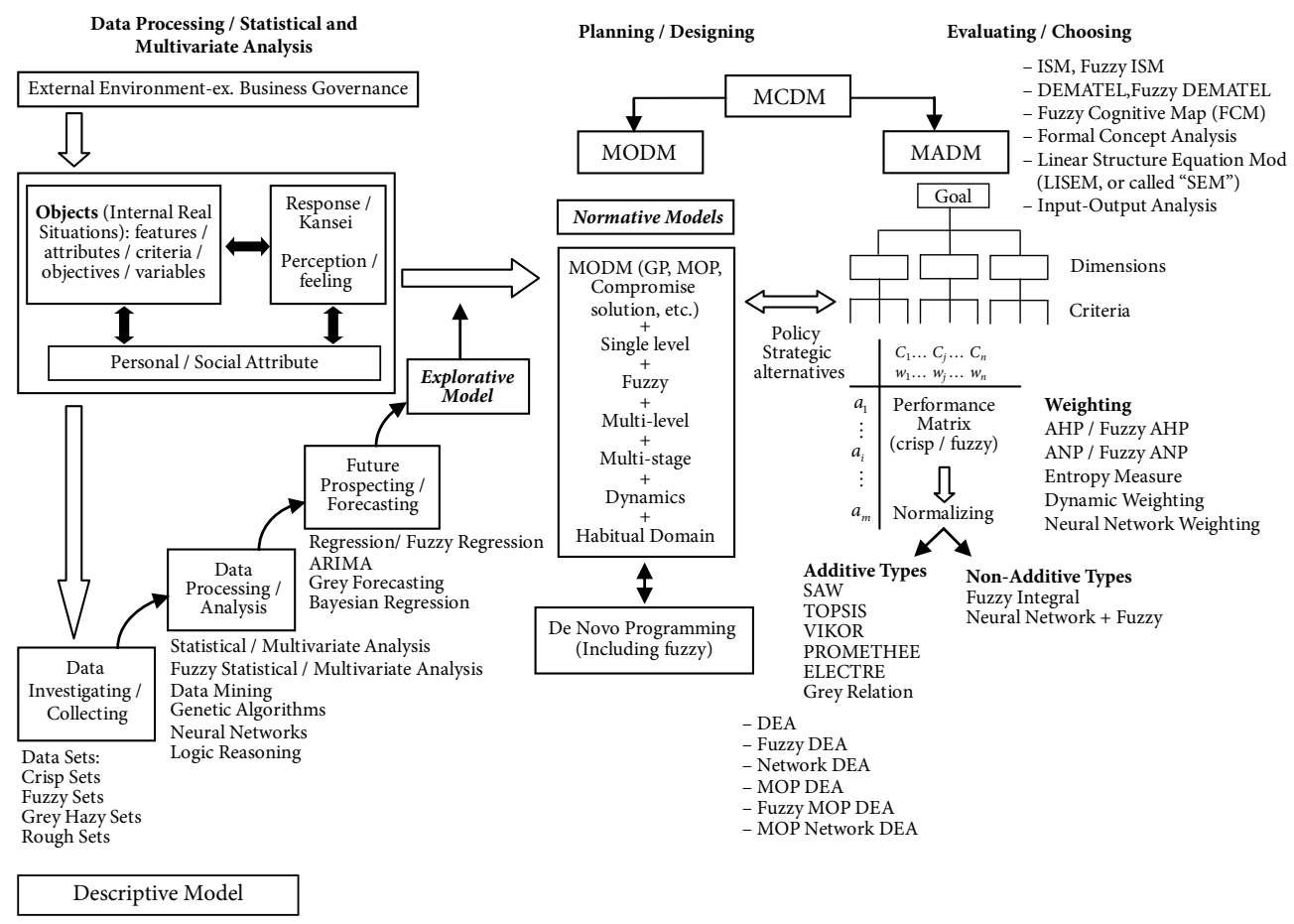

Fig. 1. The basic concepts and framework in research methods for problem-solving

inputs and outputs. DEA is comprised of various methods including fuzzy DEA, network DEA and multi-objective programming (MOP) DEA. Fig. 2 compares the traditional approach with other methods for knowledge economy. Data mining techniques may be used to process the data to support meaningful conclusions and generate useful knowledge. With the current focus on technology in business, two of the most important questions organizations must answer are how to increase market share and how to incorporate new technologies into products. Marketing efforts can be enhanced through knowledge discovering and technology can be improved through innovation and creativity in intelligent systems. MCDM could help decision-makers when faced with multiple-objective or multiple-attribute problems.

The rest of this paper is structured as follows. In Section 2, we provide supplementary material about the development of MCDM and note the differences between Multiple Objective Decision Making (MODM) and Multiple Attribute Decision Making (MADM). Important new concepts and methodologies ignored in Zavadskas and Turskis's (2011) work are discussed in Section 3. We offer concluding arguments in Section 4.

\section{Supplementary history and classification of MCDM}

MCDM refers to methods for decision making in realistic and common scenarios in which multiple, often conflicting criteria (i.e., multiple attributes or objectives) must be taken into consideration. Many such problems are related to the measurement, design, evalua- 


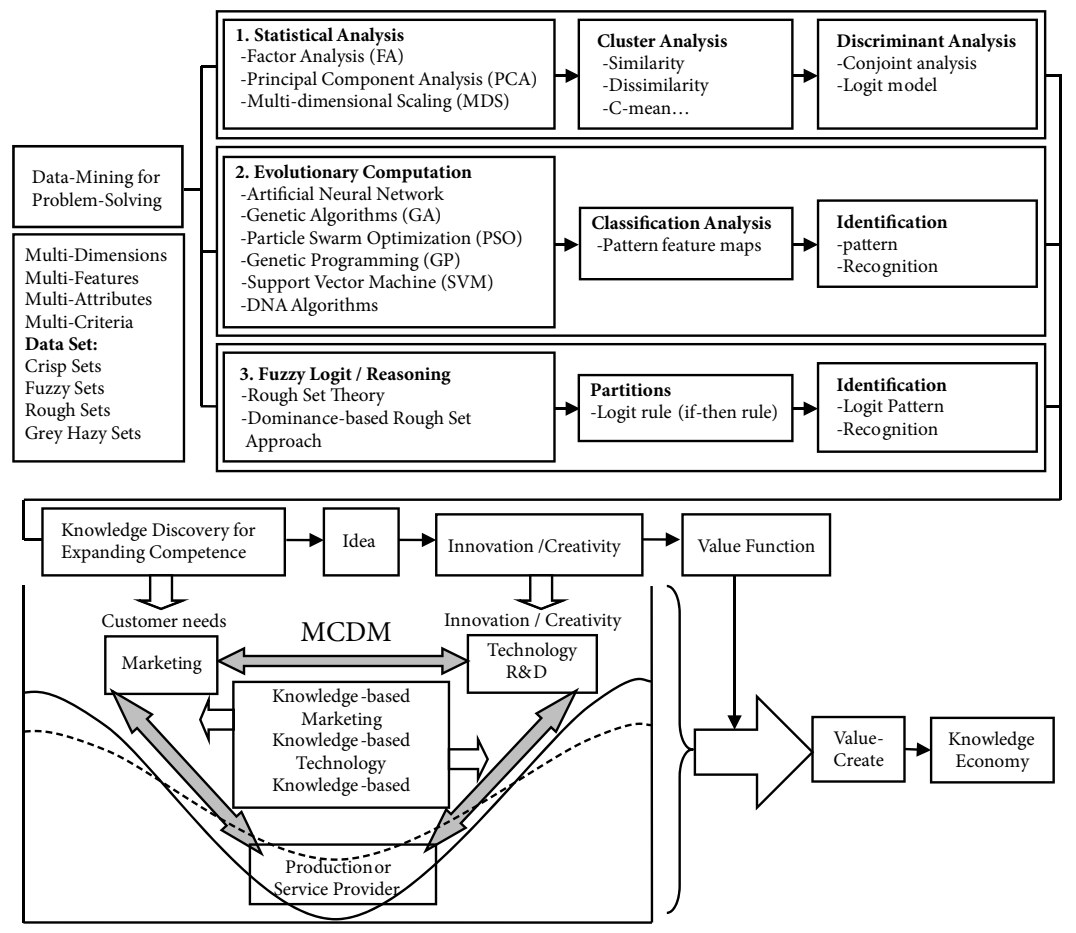

Fig. 2. Data processing for knowledge economy

tion, ranking, selection, and improvement of organizational initiatives. In this study, we will illustrate several important aspects of and new trends in MCDM that have not been adequately addressed.

(1) Planning/Design in MODM (Fig. 3): One of the primary functions of MODM is to analyze planning and design problems with multiple objectives and criteria based on a changeable decision-space in a dynamic environment (as opposed to traditional assumptions of unchangeable constraint conditions) and to bring objectives closer to their aspiration levels. One way to accomplish this is to maximize the extent of goal achievement (this is called fuzzy multi-objective programming and includes fuzzy goals, fuzzy parameters, and fuzzy variables). Alternatively, one may also redesign a decision space to achieve the desired aspiration level. This approach is called De Novo programming and is related to changeable decision-space improvement to achieve the aspiration level in objective-space (concept further explained in Appendix III). This method could be applied both in theory and practice, to real decisionmaking cases in planning or design, including changeable space (decision space and objective space). In addition to the methods described above, several other important methods have been developed since the 1990s including disaggregation methods (Zopounidis et al. 1999), preference programming (Liesiö et al. 2007) and stochastic multi-objective acceptability analysis (SMAA) (Kangas et al. 2006). The development of MODM is illustrated in Fig. 3. It is worth noting that this list is not exhaustive and is composed of only a few important authors and trends that appeared after the 1990s. 


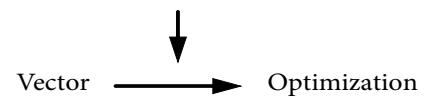

(Kuhn, Tucker 1951) (Koopmans 1951)

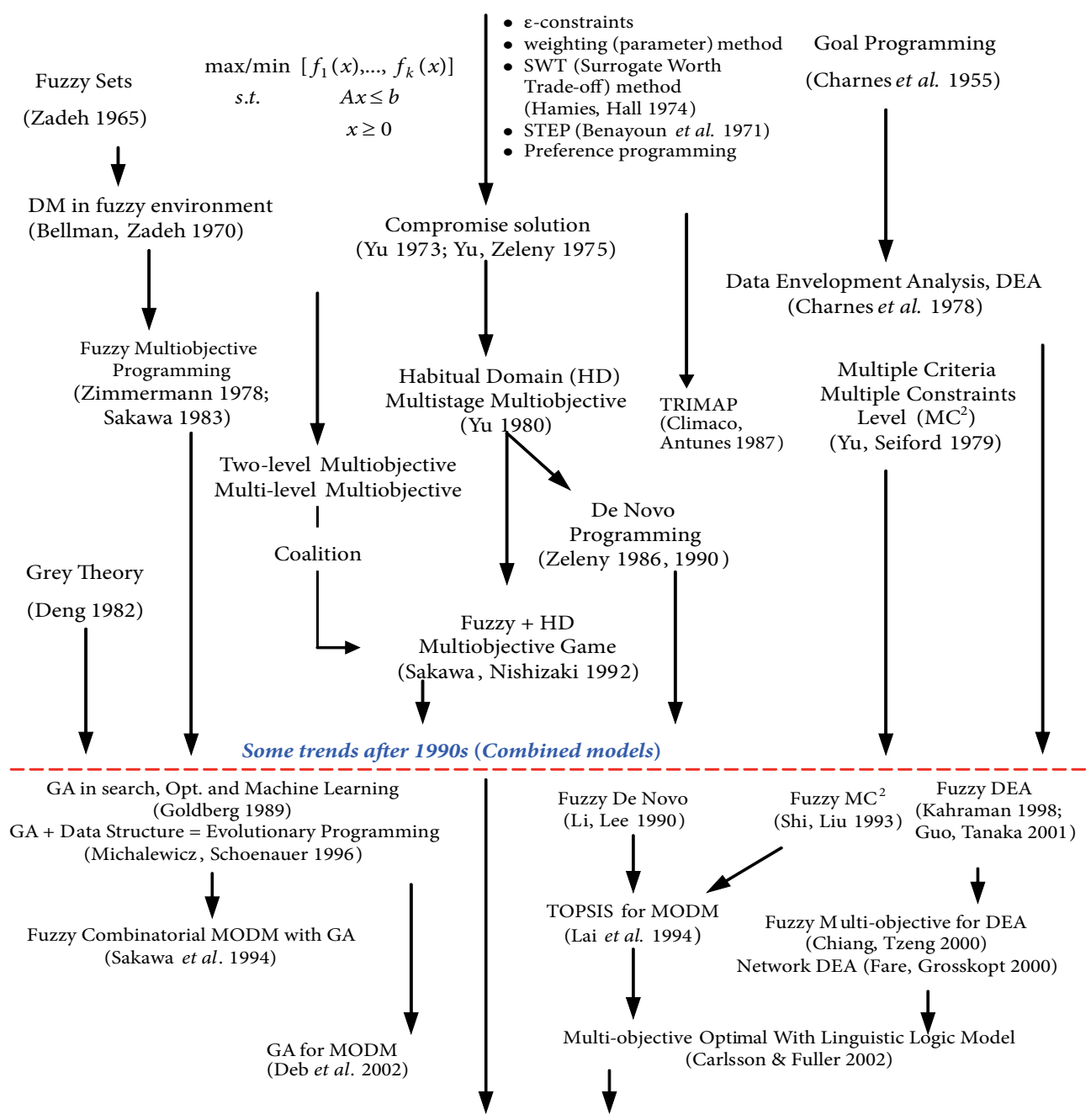

Best Alliance/Coalition through De NovoProgramming

(Huang et al. 2006)

Fuzzy + HD + Dynamic + Multistage + Multi-level Multi-objective Decision Making

(Yu, Chen 2010, Concepts on changeable space)

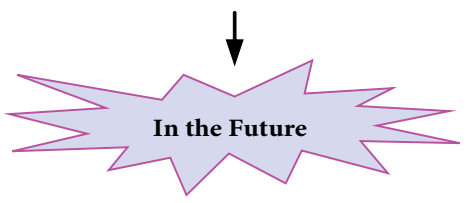

Changeable space (Decision Space and Objective Space) for De Novo MOP to improve decision-space for achieving aspiration level in objective-space (Tzeng, Huang 2012a)

Fig. 3. The development of MODM 
(2) Evaluation/Improvement/Selection in MADM (Fig. 4): One of the trends within MADM is to analyze gaps between objectives and associated aspiration levels. The Influential Network Relation Map (INRM) could help decision makers understand the relationships among dimensions and criteria and thus enable them to propose sound strategies for improvement. This goal could be accomplished with additive or super-additive (non-additive) strategies based on the DEMATEL technique. A new hybrid MCDM method (Liu et al. 2012) has been developed using the DEMATEL technique and DANP (DEMATEL-based ANP, called DANP). Several methods based on the INRM can be used to evaluate problems and enhance aspiration level achievement, including additive (e.g., VIKOR (ViseKriterijumska Optimizacija I KOmpromisno Rešenje in Serbian translates as Multicriteria Optimization and Compromise Solution method) and grey relation method) and non-additive (also referred to as superadditive e.g., Fuzzy Integrals) (Hsu et al. 2012) combined MCDM models. The INRM can be derived using a variety of techniques, including DEMATEL (Tzeng et al. 2007), Interpretive Structural Modeling (ISM) (Huang et al. 2005), Fuzzy Cognitive Map (FCM) (Yu, Tzeng 2006), Structural Equation Modeling (SEM) (Lin et al. 2010), and Formal Concept Analysis (FCA) (Fang et al. 2012). Current MADM-related trends are toward the determination of how to establish strategic systems to reduce the gaps between existing performance values and aspiration levels for each criterion. Additional points of interest include the improvement and selection of the best option for decision making in new theories (e.g., DANP) and the application of these hybrid MADM methods to real problems. Furthermore, new methods, such as COPRAS (Zavadskas et al. 2007), MULTIMOORA (Brauers, Zavadskas 2010) and LINMAP (Li 2008) have been developed or extended for solving recent economic problems.

\section{Current developments in MCDM}

In this section, we will outline several important concepts that were not considered by Zavadskas and Turskis (2011) including (1) interdependent modeling, (2) aspiration levels, (3) improvement (in addition to ranking and selection), (4) information fusion (non-additive models), and (5) changeable space in the decision and objective spaces.

\subsection{Interdependence and network structure}

Zavadskas and Turskis listed many MCDM methods, but assumed independent criteria in a hierarchical structure (such as additive modeling and weighting by AHP). In reality, the evaluation criteria are seldom independent, and the relationships between them are frequently characterized by a degree of interactivity, interdependence and feedback effects. Saaty (1996) proposed using the Analytic Network Process (ANP), which relaxes the hierarchical structure restriction. However, two questions related to the ANP model warrant attention: how to generate the influential network relationship and how to evaluate the degree of influence (Liou 2012). Tzeng developed a DEMATEL-based ANP (DANP) model that can generate an INRM to consider the various degrees of influence. In this hybrid MCDM model, DEMATEL maps out the network of influences among the various dimensions and criteria to capture the interdependence and feedback dynamics (Tzeng, Huang 2011; Hsu et al. 2012). These results 


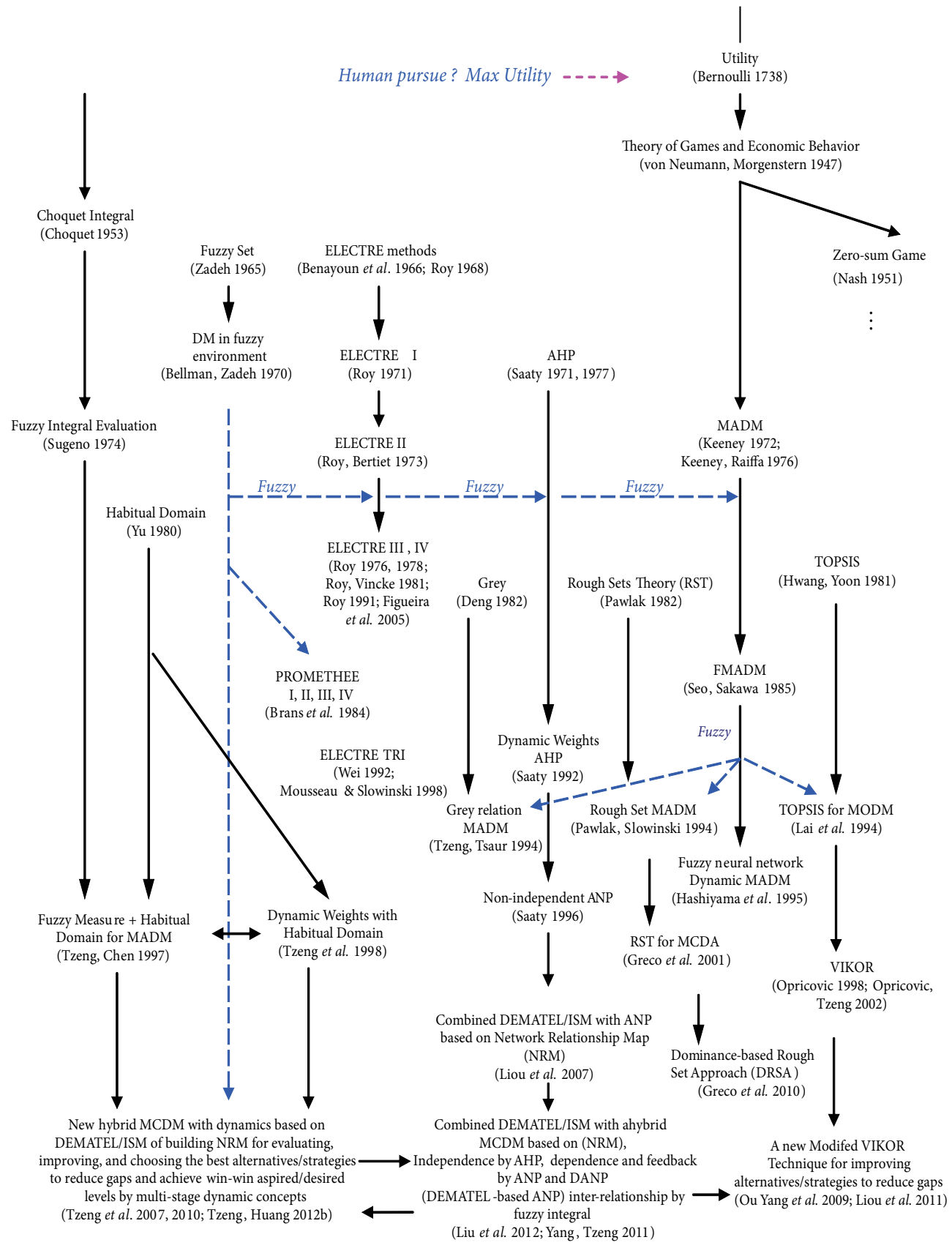

Fig. 4. The development of MADM 
are subsequently incorporated into the traditional ANP to create the new DANP method that yields more realistic weights for the respective dimensions and criteria. These weights could also be combined with other MCDM methods, such as additive types of VIKOR (Kuan et al. 2012), the grey relation (Liou et al. 2012) or non-additive types of fuzzy integrals (Larbani et al. 2011), to evaluate the performance criteria of various options and the extent to which the option achieve the desired aspiration level.

\subsection{Replacement of the relatively good existing alternatives by aspiration levels}

The traditional MADM ranks alternatives to select the best solution. However, Simon, who was awarded the Nobel Prize in economics in 1978, claimed that decision making does not obey the postulates of the "rational man." Humans do not solve problems by maximizing utility, but are "satisfiers" who set aspiration levels that a solution must satisfy. If humans are able to identify a solution that satisfies the stated aspiration levels, they accept the solution. A metaphor can be used to illustrate this difference. In the traditional method (which focuses only on ranking alternatives and selecting the overall best among them), we could pick one apple to be the benchmark from a basket of inferior apples; the benchmark is still an inferior apple. With the new concept, the decision maker sets an aspiration level as the benchmark, an alternative which might not exist in the current basket of apples, but decision-makers will understand the gaps between each alternative and the aspiration level. Decision-makers can therefore devise and implement a strategy to reduce the gaps. The current trend is toward improvement of the traditional decision-making concept, which is to choose the best from among inferior choices. The new concept is that decision makers should set an aspiration level as the benchmark and change the process to avoid this problem (Chen, Tzeng 2011; Liu et al. 2012).

\subsection{Improving but not ranking alternatives}

The development of MCDM has shifted the focus from ranking and selecting alternatives to improving their performance. The old models can only identify the gaps between competing alternatives. A new trend is to reduce the gap to achieve an aspiration level in a more realistic strategy. For example, if measures for scaling the performance value are from zero to ten $(0$, $1,2, \ldots, 10)$, we can set zero (0) to be the worst value and ten (10) to be the aspiration level. We can thus examine alternatives to reduce the gap based on an influential network relation map. This newly developed model helps decision-makers realize the gaps between current performance and aspiration levels and enhances competitiveness. Several researchers have proposed an improvement technique to lessen the gaps for each criterion obtained from VIKOR (Ou Yang et al. 2009). This technique is based on an influential relation map created by DEMATEL which is used to reduce gaps between current performance and aspiration levels. This approach can improve the traditional decision-making basic concept for alternatives ranking and selection only. It should be noted that another notably popular MCDM model, TOPSIS, has proven shortcomings with regard to ranking alternatives (Opricovic, Tzeng 2004). 


\subsection{Information fusion techniques}

Many methods based on multiple attribute utility theory (MAUT) have been proposed (e.g., the weighted sum and the weighted product methods in an additive model) to deal with MADM problems. The concept of MAUT is to aggregate all criteria to a specific dimension (the utility function) to evaluate alternatives. The main issue is to find a rational and suitable aggregation operator that represents the decision maker's preferences. Although the aggregation operator of MAUT has often been discussed (Fishburn 1970), the primary remaining challenge is the assumption of preferential independence (Hillier 2001; Grabisch 1995).

Preferential independence can be described as the preferential outcome of one criterion over another that is not influenced by the remaining criteria. However, in practical MADM application, the criteria are sometimes interactive. For example, in supplier selection, the cost, risk and quality are often interdependent. To overcome the problem of non-additivity, the Choquet integral was proposed (Choquet 1953; Sugeno 1974). The Choquet integral can represent a certain kind of interaction between criteria using the concept of redundancy and synergy and has been applied in many fields (Liou, Tzeng 2007; Chu et al. 2007). Another fusion approach can be seen in Peng et al. (2011a, 2011b).

\subsection{Changeable decision space}

In the original iteration of the MODM, it was assumed that the decision space was fixed and that the decision-maker can only choose solutions from an existing region. Zeleny $(1986,1990)$ proposed De Novo programming to redesign the feasible region to maximize the achievement levels of objectives to ideal solutions or aspiration levels (concept described in more detail in Appendix III). Tzeng applied the De Novo method of optimization in the objective space given constraints in the decision space (relaxing assumptions) to achieve the aspiration levels for all objectives (Huang et al. 2006). Tzeng also focused on applications of the new hybrid dynamic multiple-criteria decision making (HDMCDM) and changeable space, including decision space and objective space (CDOS) methods, in a wide range of industries in the fields of economics and business as a way to solve practical problems in management, create value in innovation and increase win-win competitiveness. The new concept is illustrated in Fig. 5. The traditional method looks for a solution from the Pareto solutions in the existing feasible decision space. De Novo programming pursues the ideal solution and redesigns the original decision space. The new concept has decision makers setting an aspiration level, though it may not be reachable using current resources, or simply redesigning the decision space. However, the aspiration level could be attained by expanding employees' competence set (e.g., training) or adding or changing new resources (e.g., through strategy alliance, innovation or creativity) to expand the original decision space. 


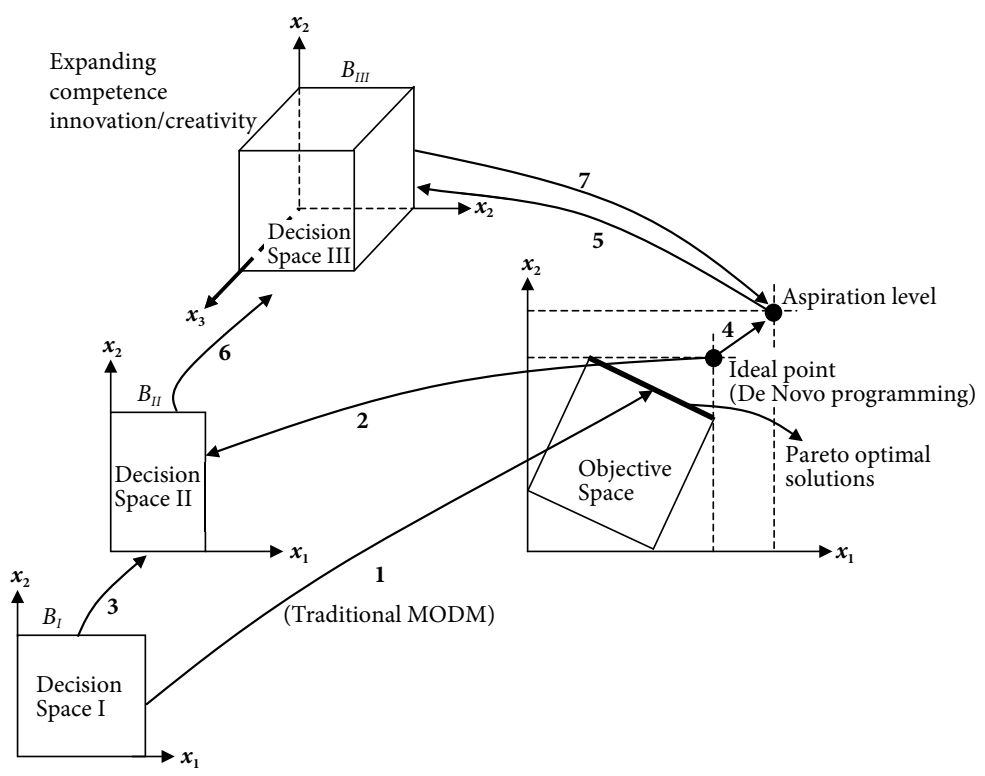

Fig. 5. The concepts of changeable decision space and aspiration level

\section{Conclusions}

This paper discusses several important concepts that were not addressed in Zavadskas and Turskis' (2011) work. We provide a historical review of MCDM with supplementary material and note several of the key authors in each stage (see Figs 3 and 4). Several significant concepts, such as building interrelationships (dependence and feedback) among criteria and improvement of criteria in general to achieve the aspiration level, are introduced. We also offer some techniques to integrate performance (information fusion) in super-additive/nonadditive value function situations. Finally, we present ways in which the decision space may be modified to achieve aspiration level of the objective space in changeable space situations. These concepts are designed to solve real problems encountered using traditional methods. This supplemental paper can be viewed as a companion to the original work and could contribute to a more comprehensive understanding of the MCDM framework and enhance the available set of techniques available for economic problem solving.

In addition to identifying new trends in MCDM, we illustrate the future outlook. The current MCDM methods depend on a decision-maker or a group of decision-makers, which group could be replaced by all stakeholders. Comparisons between statistical methods (regression or structural equation modeling (SEM)) and MCDM techniques are welcome. Future research could include the examination of more effective ways, e.g., linguistic variables or fuzzy logic, to reflect decision-makers opinions combined with new MCDM techniques. 


\section{References}

Bellman, R. E.; Zadeh, L. A. 1970. Decision-making in a fuzzy environment, Management Science 17(4): 141-164. http://dx.doi.org/10.1287/mnsc.17.4.B141

Benayoun, R.; Roy, B.; Sussman, B. 1966. ELECTRE: Use method pour guider le choix en presence de points devue multiple, Direction Scientifique. Working Paper.

Benayoun, R.; de Montgolfier, J.; Tergny, J.; Laritchev, O. 1971. Linear programming with multiple objective functions: step method (STEM), Mathematical Programming 1(1): 366-375. http://dx.doi.org/10.1007/BF01584098

Bernoulli, D. 1738. Specimen Theoriae Novae de Mensura Sortis, St. Pertersburg. (Cited in The economics of uncertainty, in K. Borch. Econometric Research Program Research Memorandum No. 54, 1963)

Brans, J. P.; Marechal, B.; Vincke, P. 1984. PROMETHEE: A new family of outranking methods in multicriteria analysis, Operational Research, IFORS'84, North Holland, 477-490.

Brauers, W. K. M.; Zavadskas, E. K. 2010. Project management by MULTIMOORA as an instrument for transition economies, Technological and Economic Development of Economy 16(1): 5-24. http://dx.doi.org/10.3846/tede.2010.01

Carlsson, C.; Fuller, R. 2002. Fuzzy reasoning in decision making and optimization. Physica-Verlag, a Springer-Verlag Company.

Charnes, A.; Cooper, W. W.; Ferguson, R. 1955. Optimal estimation of executive compensation by linear programming, Management Science 1(2): 138-151. http://dx.doi.org/10.1287/mnsc.1.2.138

Charnes, A. ; Cooper, W. W.; Rhodes, E. 1978. Measuring the efficiency of decision units, European Journal of Operational Research 2(4): 429-444. http://dx.doi.org/10.1016/0377-2217(78)90138-8

Chen, C. H.; Tzeng, G. H. 2011. Creating the aspired intelligent assessment systems for teaching materials, Expert Systems with Applications 38(10): 12168-12179. http://dx.doi.org/10.1016/j.eswa.2011.03.050

Chen, F. H.; Hsu, T. S.; Tzeng, G. H. 2011. A balanced scorecard approach to establish a performance evaluation and relationship model for hot spring hotels based on a hybrid MCDM model combining DEMATEL and ANP, International Journal of Hospitality Management 30(4): 908-932. http://dx.doi.org/10.1016/j.ijhm.2011.02.001

Chiang, C. I.; Tzeng, G. H. 2000. A multiple objective programming approach to Data envelopment analysis, in Shi, Y.; Zeleny, M. (Eds.). New Frontiers of Decision Making for the Information Technology Era. World Science Publishing Company, 270-285.

Choquet, G. 1953. Theory of capacities, Annales de L'Institut Fourier 5(1): 131-295.

Chu, M. T.; Shyu, J. Z.; Tzeng, G. H. 2007. Using non-additive fuzzy integral to assess performances of organization transformation via communities of practice, IEEE Transactions on Engineering Management 54(2): 327-339. http://dx.doi.org/10.1109/TEM.2007.893987

Climaco, J.; Antunes, C. 1987. TRIMAP - An interactive tricriteria linear programming package, Foundations of Control Engineering 12(3): 101-119.

Deb, K.; Pratap, A.; Agarwal, S.; Meyarivan, T. 2002. A fast and elitist multi-objective genetic algorithm: NSGA-II, IEEE Transactions on Evolutionary Computation 6(2): 182-187. http://dx.doi.org/10.1109/4235.996017

Deb, K.; Steuer, R. E.; Tewari, R.; Tewari, R. 2011. Bi-objective portfolio optimization using a customized hybrid NSGA-II procedure, Evolutionary Multi-criterion Optimization, in Takahashi, R. H. C., et al. (Eds.). EMO, LNCS 6576, 358-373.

Deng, J. L. 1982. Control problems of grey systems, Systems \& Control Letters 1(5): 288-294. http://dx.doi.org/10.1016/S0167-6911(82)80025-X

Fang, S. K.; Shyng, J. Y.; Lee, W. S.; Tzeng, G. H. 2012. Combined data mining techniques for exploring the preference of customers between financial companies and agents based on TCA, Knowledge-Based Systems 27(1): 137-151. http://dx.doi.org/10.1016/j.knosys.2011.09.003 
Fare, R.; Grosskopt, S. 2000. Network DEA, Socio-Ecominic Planning Sciences 34(1): 35-49. http://dx.doi.org/10.1016/S0038-0121(99)00012-9

Fishburn, P. C. 1970. Utility theory for decision making, New York: Wiley.

Figueira, J.; Mousseau, V.; Roy, B. 2005. Multiple criteria decision analysis: state of the art surveys, International Series in Operations Research \& Management Science 78(3): 133-153. http://dx.doi.org/10.1007/0-387-23081-5_4

Goldberg, D. E. 1989. Genetic Algorithms in Search, Optimization, and Machine Learning, USA: AddisonWesley.

Grabisch, M. 1995. Fuzzy integral in multicriteria decision making, Fuzzy Sets and Systems 69(3): 279-298. http://dx.doi.org/10.1016/0165-0114(94)00174-6

Greco, S.; Matarazzo, B.; Slowinski, R. 2001. Rough sets theory for multicriteria decision analysis, European Journal of Operational Research 129(1): 1-47.

Greco, S.; Matarazzo, B.; Słowiński, R. 2010. Dominance-based rough set approach to decision under uncertainty and time preference, Annals of Operations Research 176(1): 41-75. http://dx.doi.org/10.1016/S0377-2217(00)00167-3

Guo, P.; Tanaka, H. 2001. Fuzzy DEA: a perceptual evaluation method, Fuzzy Sets and Systems 119(1): 149-161. http://dx.doi.org/10.1016/S0165-0114(99)00106-2

Haimes, Y. Y.; Hall, W. A. 1974. Multiobjectives in water resource systems analysis: the surrogate worth trade off method, Water Resource Research (10)4: 615-624. http://dx.doi.org/10.1029/WR010i004p00615

Hashiyama, T.; Furuhashi, T.; Uchikawa, Y. 1995. A study on varying degrees of attention in multi-attribute decision making processes, Journal of Japan Society for Fuzzy Theory and Systems 7(4): 826-838.

Hillier, F. S. 2001. Evaluation and decision models: a critical perspective. Boston: Kluwer.

Ho, W. R. J.; Tsai, C. L.; Tzeng, G. H.; Fang, S. K. 2011. Combined DEMATEL technique with a novel MCDM model for exploring portfolio selection based on CAPM, Expert Systems with Applications 38(1): 16-25. http://dx.doi.org/10.1016/j.eswa.2010.05.058

Hsu, C. H.; Wang, F. K.; Tzeng, G. H. 2012. The best vendor selection for conducting the recycled material based on a hybrid MCDM model combining DANP with VIKOR. Resources, Conservation \& Recycling (Forthcoming). http://dx.doi.org/10.1016/j.resconrec.2012.02.009

Huang, C. Y.; Tzeng, G. H. 2007. Post-merger high technology R\&D human resources optimization through the De Novo perspective, in Shi, Y.; Olson, D. L.; Stam, A. (Eds.). Advances in Multiple Criteria Decision Making and Human Systems Management: Knowledge and Wisdom, IOS Press, 47-64.

Huang, J. J.; Tzeng, G. H.; Ong, C. S. 2005. Multidimensional data in multidimensional scaling using the analytic network process, Pattern Recognition Letters 26(6): 755-767.

http://dx.doi.org/10.1016/j.patrec.2004.09.027

Huang, J. J.; Tzeng, G. H.; Ong, C. S. 2006. Choosing best alliance partners and allocating optimal alliance resources using the fuzzy multi-objective dummy programming model, Journal of Operational Research Society 57(10): 1216-1223. http://dx.doi.org/10.1057/palgrave.jors.2602108

Hwang, C. L.; Yoon, K. 1981. Multiple Attribute Decision Making: Methods and Applications, Lecture Notes in Economics and Mathematical Systems, New York, Berlin: Springer-Verlag. http://dx.doi.org/10.1007/978-3-642-48318-9

Kahraman, C. 1998. Data envelopment analysis using fuzzy concept, in The $28^{\text {th }}$ IEEE International Symposium on Multiple-Value Logic, Fukuoka, Japan, 338-343.

Kangas, A.; Kangas, J.; Lahdelma, R.; Salminen, P. 2006. Using SMAA-2 method with dependent uncertainties for strategic forest planning, Forest Policy and Economics 9(2): 113-125.

http://dx.doi.org/10.1016/j.forpol.2005.03.012

Keeney, R. L. 1972. Utility functions for multiattributed consequences, Management Science 18(5): 276-287. http://dx.doi.org/10.1287/mnsc.18.5.276 
Keeney, R. L.; Raiffa, H. 1976. Decision with multiple objectives: Preferences and value tradeoffs. New York: John Wiley and Sons.

Koopmans, T. C. 1951. Analysis of production as an efficient combination of activities, in Koopmans, T. C. (Ed.). Activity Analysis of Production and Allocation, Cowles Comm. Monogr., 13, New York: John Wiley, 33-97.

Kuan, M. J.; Tzeng, G. H.; Hsiang, C. C. 2012. Exploring the quality assessment system for new product development process by combining DANP with MCDM model, International Journal of Innovative Computing, Information and Control (Special issue), (Forthcoming).

Kuhn, H. W.; Tucker, A. W. 1951. Nonlinear programming, in Proceedings of the second Berkeley Symposium on Mathematical Statistics and Probability, 481-492.

Lai, Y. J.; Liu, T. Y.; Hwang, C. L. 1994. TOPSIS for MODM, European Journal of Operational Research 76(3): 486-500. http://dx.doi.org/10.1016/0377-2217(94)90282-8

Larbani, M.; Huang, C. Y.; Tzeng, G. H. 2011. A novel method for fuzzy measure identification, International Journal of Fuzzy Systems 13(1): 24-34.

Li, D. F. 2008. Extension of the LINMAP for multiattribute decision making under Atanassov's intuitionistic fuzzy environment, Fuzzy Optimization and Decision Making 7(1): 17-34. http://dx.doi.org/10.1007/s10700-007-9022-x

Li, R. J.; Lee, E. S. 1990. Fuzzy approaches to multicriteria De Novo programs, Journal of Mathematical Analysis and Applications 153(1): 13-20. http://dx.doi.org/10.1016/0022-247X(90)90268-K

Liesiö, J.; Mild, P.; Salo, A. 2007. Preference programming for robust portfolio modeling and project selection, European Journal of Operational Research 181(3): 1488-1505. http://dx.doi.org/10.1016/j.ejor.2005.12.041

Lin, C. S.; Tzeng, G. H.; Chin, Y. C.; Chang, C. C. 2010. Recommendation sources on the intention to use e-books in academic digital libraries, The Electronic Library 28(6): 844-857. http://dx.doi.org/10.1108/02640471011093534

Liou, J. J. H. 2012. Developing an integrated model for the selection of strategic alliance partners in the airline industry, Knowledge-Based Systems 28(1):59-67. http://dx.doi.org/10.1016/j.knosys.2011.11.019

Liou, J. J. H.; Tzeng, G. H. 2007. A non-additive model for evaluating airline service quality, Journal of Air Transport Management 13(3): 131-138. http://dx.doi.org/10.1016/j.jairtraman.2006.12.002

Liou, J. J. H.; Tsai, C. Y.; Lin, R. H.; Tzeng, G. H. 2011. A modified VIKOR multiple-criteria decision method for improving domestic airlines service quality, Journal of Air Transport Management 17(2): 57-61. http://dx.doi.org/10.1016/j.jairtraman.2010.03.004

Liou, J. J. H.; Tzeng, G. H.; Chang, H. C. 2007. Airline safety measurement using a hybrid model, Journal of Air Transport Management 13(4): 243-49. http://dx.doi.org/10.1016/j.jairtraman.2007.04.008

Liou, J. J. H.; Tzeng, G. H.; Hsu, C. C.; Yeh, W. C. 2012. Reply to "Comment on using a modified grey relation method for improving airline service quality”, Tourism Management 33(3): 719-720. http://dx.doi.org/10.1016/j.tourman.2011.07.007

Liu, C. H.; Tzeng, G. H.; Lee, M. H. 2012. Improving tourism policy implementation - the use of hybrid MCDM models, Tourism Management 33(2): 239-488. http://dx.doi.org/10.1016/j.tourman.2011.05.002

Michalewicz, Z.; Schoenauer, M. 1996. Evolutionary algorithms for constrained parameter optimization problems, Evolutionary Computation 4(1): 1-32. http://dx.doi.org/10.1162/evco.1996.4.1.1

Mousseau, V; Slowinski, R. 1998. Inferring an ELECTRE TRI model from assignment examples, Journal of Global Optimization 12(12): 157-174. http://dx.doi.org/10.1023/A:1008210427517

Nash, J. 1951. Non-cooperative game, The Annals of Mathematics 54(2): 286-295. http://dx.doi.org/10.2307/1969529 
Opricovic, S. 1998. Multicriteria optimization of civil engineering systems. Belgrade: Faculty of Civil Engineering (in Serbian).

Opricovic, S.; Tzeng, G. H. 2002. Multicriteria planning of post-earthquake sustainable reconstruction, Computer-Aided Civil and Infrastructure Engineering 17(3): 211-220.

http://dx.doi.org/10.1111/1467-8667.00269

Opricovic, S.; Tzeng, G. H. 2004. Compromise solution by MCDM Methods: a comparative analysis of VIKOR and TOPSIS, European Journal of Operational Research 156(2): 445-455. http://dx.doi.org/10.1016/S0377-2217(03)00020-1

Opricovic, S.; Tzeng, G. H. 2007. Extended VIKOR method in comparison with outranking methods, European Journal of Operational Research 178(2): 514-529. http://dx.doi.org/10.1016/j.ejor.2006.01.020

Ou Yang, Y. P.; Shieh, H. M.; Tzeng, G. H. 2009. A VIKOR-based multiple criteria decision method for improving information security risk, International Journal of Information Technology and Decision Making 8(2): 267-287. http://dx.doi.org/10.1142/S0219622009003375

Pawlak, Z. 1982. Rough sets, International Journal of Computer and Information Science 11(5): 341-356. http://dx.doi.org/10.1007/BF01001956

Pawlak, Z.; Stowinski, R. 1994. Rough set approach to multi-attribute decision analysis, European Journal of Operational Research 72(3): 443-459. http://dx.doi.org/10.1016/0377-2217(94)90415-4

Peng, Y.; Kou, G.; Wang, G.; Shi, Y. 2011a. FAMCDM: a fusion approach of MCDM methods to rank multiclass classification algorithms, Omega 39(6): 677-689. http://dx.doi.org/10.1016/j.omega.2011.01.009

Peng, Y.; Kou, G.; Wang, G.; Wu, W.; Shi, Y. 2011b. Ensemble of software defect predictors: an AHPbased evaluation method, International Journal of Information Technology \& Decision Making 10(1): 187-206. http://dx.doi.org/10.1142/S0219622011004282

Roy, B. 1968. Classement et choix en presence de points de vue multiples (la methode Electre), Revue Francaise d'Informatique et de Recherche Operationnelle 8(1): 57-75.

Roy, B. 1971. Problems and methods with multiple objective functions, Mathematical Programming 1(1): 239-266. http://dx.doi.org/10.1007/BF01584088

Roy, B.; Bertier, P. 1973. La méthode ELECTRE II - Une application aumedia-planning, in Ross, M. (Ed.). OR 72: 291-302, North Holland, Amsterdam.

Roy, B. 1976. From optimization to multicriteria decision aid: three main operational attitudes, in Thiriez, H.; Zionts, S. (Eds.). Multiple Criteria Decision Making, vol. 130 of Lecture Notes in Economics and Mathematical Systems, Berlin: Springer-Verlag, 1-34.

Roy, B. 1978. ELECTRE III: Un algorithme de classements fondé sur une représentation floue des préférences en présence de critéres multiples, Cahiers du Centre d'Etudes de Recherche Opérationnelle 20: $3-24$.

Roy, B.; Vincke, Ph. 1981. Multicriteria analysis: survey and new directions, European Journal of Operational Research 8(3): 207-218. http://dx.doi.org/10.1016/0377-2217(81)90168-5

Roy, B. 1991. The outranking approach and the foundations of Electre methods, Theory and Decision 31(1): 49-73. http://dx.doi.org/10.1007/BF00134132

Saaty, T. 1971. On polynomials and crossing numbers of complete graphs, Journal of Combinatorial Theory 10(2): 183-184. http://dx.doi.org/10.1016/0097-3165(71)90024-0

Saaty, T. 1977. A scaling method for priorities in hierarchical structures, Journal of Mathematical Psychology 15(3): 234-281. http://dx.doi.org/10.1016/0022-2496(77)90033-5

Saaty, T. 1992. A natural way to make momentous decisions, Journal of Science and Industrial Research 51: 561-571.

Saaty, T. L. 1996. Decision making with dependence and feedback: analytic network process, Pittsburgh: RWS. 
Sakawa, M. 1983. Interactive computer programs for fuzzy linear programming with multiple objectives, International Journal of Man-Machine Studies 18(5): 489-503.

http://dx.doi.org/10.1016/S0020-7373(83)80022-4

Sakawa, M.; Nishizaki, I. 1992. A solution concept based on fuzzy decision in n-person cooperative games, in Trappl, R. (Ed.). Cybernetics and Systems Research'92, World Scientific Publishing, 423-430.

Sakawa, M.; Inuiguchi, M.; Sunada, H.; Sawada, K. 1994. Fuzzy multiobjective combinatorial optimization through revised genetic algorithms, Japanese Journal of Fuzzy Theory and Systems 6(1): 177-186.

Seo, F; Sakawa, M. 1985. Fuzzy multiattribute utility analysis for collective choice, IEEE Transactions on Systems, Man, \& Cybernetics 15(1): 45-53. http://dx.doi.org/10.1109/TSMC.1985.6313393

Shi, Y.; Liu, Y. H. 1993. Fuzzy potential solutions in multi-criteria and multi-constraint levels linear programming problems, Fuzzy Sets and Systems 60(2): 163-179.

http://dx.doi.org/10.1016/0165-0114(93)90344-H

Sugeno, M. 1974. Theory of fuzzy integrals and its applications: Ph.D. thesis. Tokyo Institute of Technology, Tokyo, Japan.

Tzeng, G. H.; Chen, T. Y.; Wang, J. C. 1998. A weight-assessing method with habitual domains, European Journal of Operational Research 110(2): 342-367. http://dx.doi.org/10.1016/S0377-2217(97)00246-4

Tzeng, G. H.; Chiang, C. H.; Li, C. W. 2007. Evaluating intertwined effects in e-learning programs: a novel hybrid MCDM model based on factor analysis and DEMATEL, Expert Systems with Applications 32(4): 1028-1044. http://dx.doi.org/10.1016/j.eswa.2006.02.004

Tzeng, G. H.; Chen, J. J.; 1997. Developing Taipei automobile driving cycles for emissions, Energy \& Environment 8(3): 227-238.

Tzeng, G. H.; Chen, W. H.; Yu, R.; Shih, M. L. 2010. Fuzzy decision maps- a generalization of the DEMATEL methods, Soft Computing 14(11): 1141-1150. http://dx.doi.org/10.1007/s00500-009-0507-0

Tzeng, G. H.; Huang, J. J. 2011. Multiple Attribute Decision Making: Methods and Applications, CRC Press, Taylor \& Francis Group, a Chapman \& Hall Book.

Tzeng, G. H.; Huang, J. J. 2012a. Multiple Objective Decision Making: Methods and Applications, CRC Press, Taylor \& Francis Group, a Chapman \& Hall Book.

Tzeng, G. H.; Huang, C. Y. 2012b. Combined DEMATEL technique with hybrid MCDM methods for creating the aspired intelligent global manufacturing \& logistics systems, Annals of Operations Research (Forthcoming). http://dx.doi.org/10.1007/s10479-010-0829-4

Tzeng, G. H.; Tasur, S. H. 1994. The multiple criteria evaluation of grey relation model, The Journal of Grey System 6(2): 87-108.

Von Neumann, J.; Morgenstern, O. 1947. The Theory of Games and Economic Behavior, $2^{\text {nd }}$ ed. Princeton, NJ.: Princeton University Press.

Wei, Y. 1992. Methodological aspects and a user's guide of the computer program, Report NO. LAMSADED -92-74, University of Paris-Dauphine, Lamsade, France.

Yang, J. L.; Tzeng, G. H. 2011. An integrated MCDM technique combined with DEMATEL for a novel cluster-weighted with ANP method, Expert Systems with Applications 38(3): 1417-1424. http://dx.doi.org/10.1016/j.eswa.2010.07.048

Yu, P. L. 1973. A class of solutions for group decision problems, Management Science 19(8): 136-946. http://dx.doi.org/10.1287/mnsc.19.8.936

Yu, P. L. 1980. Behavior bases and habitual domains of human decision/behavior: concepts and applications, in Fandel, G.; Gal, T. (Eds.). Multiple Criteria Decision-Making: Theory and Applications, New York: Springer-Verlag, 11-539. http://dx.doi.org/10.1007/978-3-642-48782-8_34

Yu, P. L.; Chen, Y. C. 2010. Dynamic multiple criteria decision making in changeable spaces: from habitual domains to innovation dynamics, Annals of Operations Research (Forthcoming).

http://dx.doi.org/10.1007/s10479-010-0750-x 
Yu, P. L.; Seiford, L. 1979. Potential solutions of linear systems: the multicriteria, multiple constraint level program, Journal of Mathematical Analysis and Applications 69(2): 283-303.

http://dx.doi.org/10.1016/0022-247X(79)90143-4

Yu, P. L.; Zeleny, M. 1975. The set of all nondominated solutions in linear cases and a multicriteria simplex method, Journal of Mathematical Analysis and Applications 49(2): 430-468.

http://dx.doi.org/10.1016/0022-247X(75)90189-4

Yu, R. C.; Tzeng, G. H. 2006. A soft computing method for multi-criteria decision making with dependence and feedback, Applied Mathematics and Computation 180(1): 63-75. http://dx.doi.org/10.1016/j.amc.2005.11.163

Zadeh, L. 1965. Fuzzy sets, Information and Control 8(3): 338-53. http://dx.doi.org/10.1016/S0019-9958(65)90241-X

Zavadskas, E. K.; Kaklauskas, A.; Peldschus, F.; Turskis, Z. 2007. Multi-attribute assessment of road design solutions by using the COPRAS method, Baltic Journal of Road and Bridge Engineering 2(4): 195-203.

Zavadskas, E. K.; Turskis, Z. 2011. Multiple criteria decision making (MCDM) methods in economics: an overview, Technological and Economic Development of Economy 17(2): 397-427. http://dx.doi.org/10.3846/20294913.2011.593291

Zeleny, M. 1986. Optimal system design with multiple criteria: de novo programming approach, Engineering Costs and Production Economics 10(1): 89-95. http://dx.doi.org/10.1016/0167-188X(86)90029-7

Zeleny, M. 1990. Optimizing given systems vs. designing optimal systems: the De Novo programming approach, International Journal of General Systems 17(3): 295-307. http://dx.doi.org/10.1080/03081079008935113

Zimmermann, H. J. 1978. Fuzzy programming and linear programming with several objective functions, Fuzzy Sets and Systems 1(1): 45-55. http://dx.doi.org/10.1016/0165-0114(78)90031-3

Zopounidis, C.; Doumpos, M.; Zanakis, S. H. 1999. Stock evaluation using a preference disaggregation methodology, Decision Sciences 30(2):313-336. http://dx.doi.org/10.1111/j.1540-5915.1999.tb01612.x

\section{APPENDIX I. \\ An example of the DEMATEL method for building influential network relation maps}

If a manager wanted to understand the network relationship between evaluating attributes and developing strategies for the reduction of gaps between the aspiration levels of a company and its suppliers (such as the VIKOR method), he or she could use the DEMATEL method. The DEMATEL method reveals the total and net degrees of influence of attributes. The INRM can provide ideas for improvement. The steps in the DEMATEL method and INRM can be summarized as follows:

Step 1. Calculate the direct relation average matrix.

Respondents are asked to propose the degree of direct influence each perspective or criterion i exerts on each perspective/criterion $\mathrm{j}$, which is denoted by dij, using a scale such that $0,1,2,3$ and 4 represent the range from "no influence" (0) to "very high influence" (4). 
A direct relation matrix is produced for each respondent, and an average matrix A is subsequently derived from the mean of the same perspectives and criteria in the respective direct matrices for all respondents. The average matrix $\mathrm{A}$ is given by:

$$
\boldsymbol{A}=\left[\begin{array}{ccccc}
a_{11} & \cdots & a_{1 j} & \cdots & a_{1 n} \\
\vdots & & \vdots & & \vdots \\
a_{i 1} & \cdots & a_{i j} & \cdots & a_{i n} \\
\vdots & & \vdots & & \vdots \\
a_{n 1} & \cdots & a_{n j} & \cdots & a_{n n}
\end{array}\right] .
$$

Step 2. Calculate the initial direct influence matrix.

The initial direct influence matrix X can be obtained by normalizing the average matrix A. In addition, the matrix X can be obtained through equations (2) and (3), in which all principal diagonal criteria are equal to zero.

$$
s=\min \left\{\frac{\boldsymbol{X}=\boldsymbol{s} \cdot \boldsymbol{A}}{\max _{i} \sum_{j=1}^{n}\left|d_{i j}\right|}, \frac{1}{\max _{j} \sum_{i=1}^{n}\left|d_{i j}\right|}\right\} .
$$

Step 1: Derive the total influence matrix

A continuous decrease of the indirect effects of problems along the powers of $\boldsymbol{X}$, e.g., $\boldsymbol{X}^{2}, \boldsymbol{X}^{3}, \ldots, \boldsymbol{X}^{h}$ and $\lim _{h \rightarrow \infty} \boldsymbol{X}^{h}=[0]_{n \times n}$, where $\boldsymbol{X}=\left[x_{i j}\right]_{n \times n}, 0 \leq x_{i j}<1,0<\sum_{i} x_{i j} \leq 1$, $0<\sum_{j} x_{i j} \leq 1$ and at least one column sum $\sum_{j} x_{i j}$ or one row sum $\sum_{i} x_{i j}$ equals 1 . The total influence matrix $\boldsymbol{T}$ is

$$
\boldsymbol{T}=\boldsymbol{X}+\boldsymbol{X}^{2}+\ldots+\boldsymbol{X}^{h}=\boldsymbol{X}(\boldsymbol{I}-\boldsymbol{X})^{-1}, \text { when } \lim _{h \rightarrow \infty} \boldsymbol{X}^{h}=[0]_{n \times n},
$$

where $\boldsymbol{T}=\left[t_{i j}\right]_{n \times n}$, for $i, j=1,2, \ldots, n$ and $(\boldsymbol{I}-\boldsymbol{X})(\boldsymbol{I}-\boldsymbol{X})^{-1}=\boldsymbol{I}$. Additionally, this method presents each row sum and column sum of influential matrix $\boldsymbol{T}=\left[t_{i j}\right]_{n \times n}$ separately, expressed as vector $r$ and vector $s$ through the Eqs. (5) - (6):

$$
\begin{gathered}
\boldsymbol{r}=\left(r_{i}\right)_{n \times 1}=\left[\sum_{j=1}^{n} t_{i j}\right]_{n \times 1}, \\
\boldsymbol{s}=\left(s_{j}\right)_{n \times 1}=\left(s_{j}\right)_{1 \times n}^{\prime}=\left[\sum_{i=1}^{n} t_{i j}\right]_{1 \times n}^{\prime},
\end{gathered}
$$

where the superscript ' denotes transpose; ri denotes the row sum of the ith row of matrix $T$ and shows the sum of the direct and indirect effects of perspective or criterion $i$ on the other perspectives and criteria. Similarly, $s_{j}$ denotes the column sum of the jth column of matrix $T$ and shows the sum of direct and indirect effects that perspective or criterion $\mathrm{j}$ has received from the other perspectives and criteria. In addition, when $i=j$ (i.e., the sum of the row and column aggregates) $r_{i}+s_{i}$ provides an index of the strength of influence given and received, that is, $r_{i}+s_{i}$ illustrates the extent to which criterion $i$ plays a central role in 
the problem. If $r_{i}-s_{i}$ is positive, then criterion $i$ affects other criteria, and if $r_{i}-s_{i}$ is negative, then criterion $i$ is influenced by other criteria. Based on the total influence matrix, the INRM can be draw as Fig. A1.

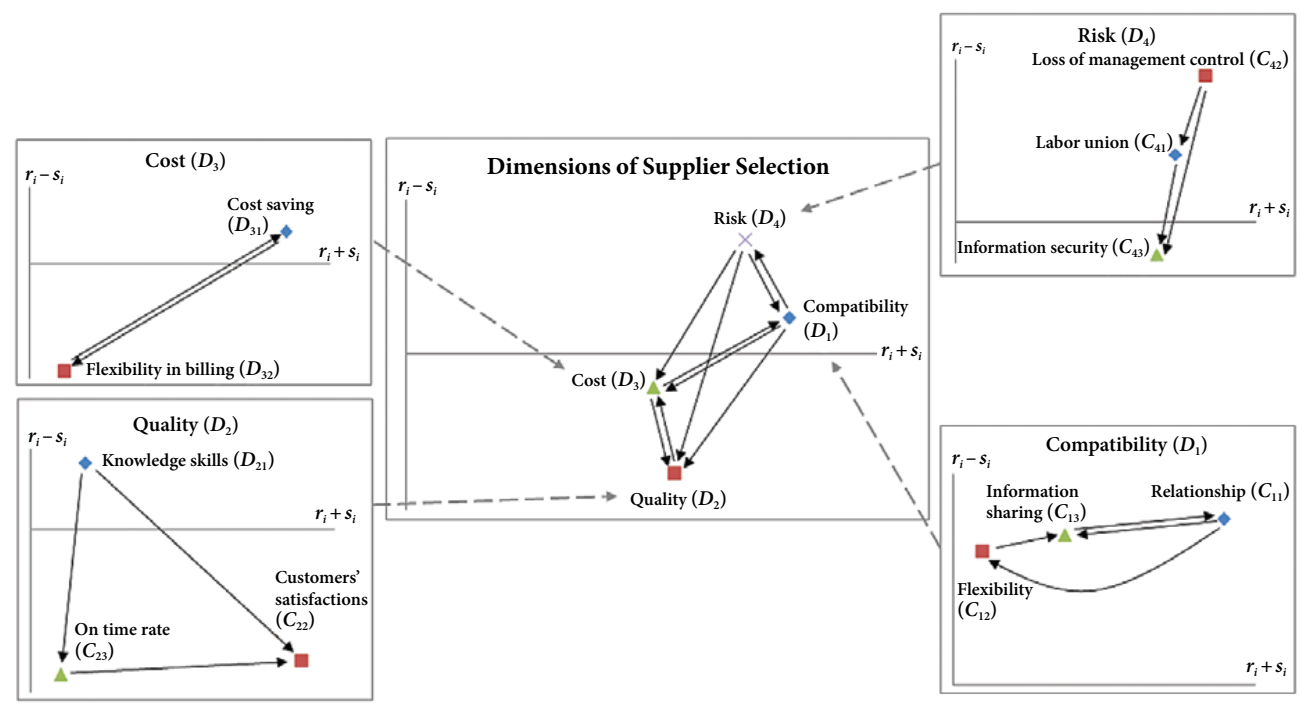

Fig. A1. Influential network relationship map for supplier selection

\section{APPENDIX II.}

\section{VIKOR method for reducing performance gaps to improve the alternatives}

Opricovic and Tzeng (2004) proposed the compromise ranking method (VIKOR) as one applicable technique to implement within MCDM. Suppose that the feasible alternatives are represented by $V_{1}, V_{2}, \ldots, V_{k}, \ldots, V_{m}$. The performance scores of alternative $V_{k}$ and the $j$ th criterion is denoted by $f_{k j}$. $w_{j}$ is the influential weight (relative importance) of the $j$ th criterion, where $j=1,2, \ldots, n$ and $n$ is the number of criteria. Development of the VIKOR method began with the following form of the $L_{p}$-metric:

$$
L_{k}^{p}=\left\{\sum_{j=1}^{n}\left[w_{j}\left(\left|f_{j}^{*}-f_{k j}\right|\right) /\left(\left|f_{j}^{*}-f_{j}^{-}\right|\right)\right]^{p}\right\}^{1 / p},
$$

where $1 \leq p \leq \infty ; k=1,2, \ldots, m$ and influential weight $w_{j}$ is derived from the DANP. $L_{k}^{p=1}$ (as $S_{k}$ ) and $L_{k}^{p=\infty}\left(\right.$ as $\left.Q_{k}\right)$ are used by the VIKOR method to formulate the ranking and gap measures.

$$
\begin{gathered}
S_{k}=L_{k}^{p=1}=\sum_{j=1}^{n}\left[w_{j}\left(\left|f_{j}^{*}-f_{k j}\right|\right) /\left(\left|f_{j}^{*}-f_{j}^{-}\right|\right)\right], \\
Q_{k}=L_{k}^{p=\infty}=\max _{j}\left\{\left(\left|f_{j}^{*}-f_{k j}\right|\right) /\left(\left|f_{j}^{*}-f_{j}^{-}\right|\right) \mid j=1,2, \ldots, n\right\} .
\end{gathered}
$$


The compromise solution $\min _{k} L_{k}^{p}$ showed the synthesized gap to be minimized, and it will be selected such that its value will be the closest to the aspiration level. In addition, the group utility is emphasized when $p$ is small (such as $p=1$ ). If, however, $\mathrm{p}$ approaches infinity, the individual maximum regrets/gaps obtain more importance in prior improvement in each dimension/criterion. Consequently, $\min _{k} S_{k}$ stresses the maximum group utility; however, $\min _{k} Q_{k}$ stresses the selection of the minimum and maximum individual regrets/gaps for a demonstrated improvement of priority. The compromise-ranking algorithm VIKOR has four steps according to the abovementioned factors:

Obtain an aspiration or tolerable level. We calculated the best $f_{j}^{*}$ values (aspiration level) and the worst $f_{j}^{-}$values (tolerable level) of all criterion functions, $j=1,2, \ldots, n$. Suppose the $j$ th function denotes benefits: $f_{j}^{*}=\max _{k} f_{k j}$ and $f_{j}^{-}=\min _{k} f_{k j}$ (these values can also be set by decision makers) i.e., $f_{j}^{*}$ is the aspiration level and $f_{j}^{-}$is the worst value. In this research, we use the performance scores from 0 to 10 (very bad $\leftarrow 0,1,2, \ldots, 9,10 \rightarrow$ very good) in questionnaires; therefore, the aspiration level can be set at a score of 10 and the worst value at a score of zero. Therefore, in this research and contrary to traditional research, we set $f_{j}^{*}=10$ as the aspiration level and $f_{j}^{-}=0$ as the worst value. This approach avoids the problems associated with choosing the best among inferior choices (i.e., avoids picking the best apple from a barrel of rotten apples). The steps can be thought of as follows:

Step 1: First, an original rating matrix can be converted into a normalized weight-rating matrix with the following equation.

$$
r_{k j}=\left(\left|f_{j}^{*}-f_{k j}\right|\right) /\left(\left|f_{j}^{*}-f_{j}^{-}\right|\right) .
$$

Step 2: Calculate the group utility mean and maximum regret. The values can be computed using $S_{k}=\sum_{j=1}^{n} w_{j} r_{k j}$ (the average synthesized gap for all criteria) and $Q_{k}=\max _{j}\left\{r_{k j} \mid j=1,2, \ldots, n\right\}$ (the maximum gap in $k$ criterion for priority improvement) respectively.

Step 3: Calculate the index value using Eq. (A11).

$$
R_{k}=v\left(S_{k}-S^{*}\right) /\left(S^{-}-S^{*}\right)+(1-v)\left(Q_{k}-Q^{*}\right) /\left(Q^{-}-Q^{*}\right),
$$

where $k=1,2, \ldots, m, S^{*}=\min _{i} S_{i}$ or $S^{*}=0$ (when all criteria have been achieved to the aspiration level) and $S^{-}=\max _{i} S_{i}$ or $S^{-}=1$ (the worst situation); $Q^{*}=\min _{i} Q_{i}$ or setting $Q^{*}=0$ and $Q^{-}=\max _{i} Q_{i}$ or setting $Q^{-}=1$, and $v$ is presented as the weight of the strategy of the maximum group utility (priority improvement). Conversely, $1-v$ is the weight of individual regret. Therefore, we can rewrite $R_{k}=v S_{k}+(1-v) Q_{k}$, when $S^{*}=0, S^{-}=1, Q^{*}=0$ and $Q^{-}=1$. 


\section{APPENDIX III.}

\section{Extension of De Novo programming to changeable spaces for an MOP problem}

Multi-objective programming (MOP) problems can mathematically be represented as

$$
\begin{array}{ll}
\max \left[f_{1}(\boldsymbol{x}), f_{2}(\boldsymbol{x}), \ldots, f_{k}(\boldsymbol{x})\right] \Rightarrow \text { Objective space } \\
\text { s.t. } \quad \boldsymbol{A} \boldsymbol{x} \leq \boldsymbol{b} \Rightarrow \text { Decision space, }\left\{\begin{array}{l}
\boldsymbol{p}^{\prime} \boldsymbol{A} \boldsymbol{x} \leq \boldsymbol{p}^{\prime} \boldsymbol{b}=\boldsymbol{B} \\
\boldsymbol{x} \geq \mathbf{0}
\end{array}\right.
\end{array}
$$

where $\boldsymbol{p}$ denotes a vector of unit prices of resources. The superscript ' denotes transpose.

Traditional MOP problems find the objective space subject to the decision space, which assumes that the decision space cannot be changed. We developed new "changeable spaces" method to relax these assumptions for MOP problems based on De Novo programming (Zeleny 1986, 1990).

\section{$\min c x$}

s.t. $f_{i}(\boldsymbol{x}) \geq f_{i}^{*}, i=1,2, \ldots, k$ (or setting $f_{i}^{*}$ to be an aspiration level) $\boldsymbol{x} \geq \mathbf{0}$,

where vector $\boldsymbol{c}=\boldsymbol{p}^{\prime} \boldsymbol{A}$ denotes unit prices of decision variables, and $f_{i}^{*}$ denotes the ideal point of objective $i$ (we also can set $f_{i}^{*}$ to be an aspiration level).

\section{[Example]}

Graph Example

$\max f_{1} \ldots .$. profit

$\max f_{2} \ldots .$. quality

Reshaping the feasible set to include the missing "Good" alternative

Given design with natural quality - profit trade-offs as follows:

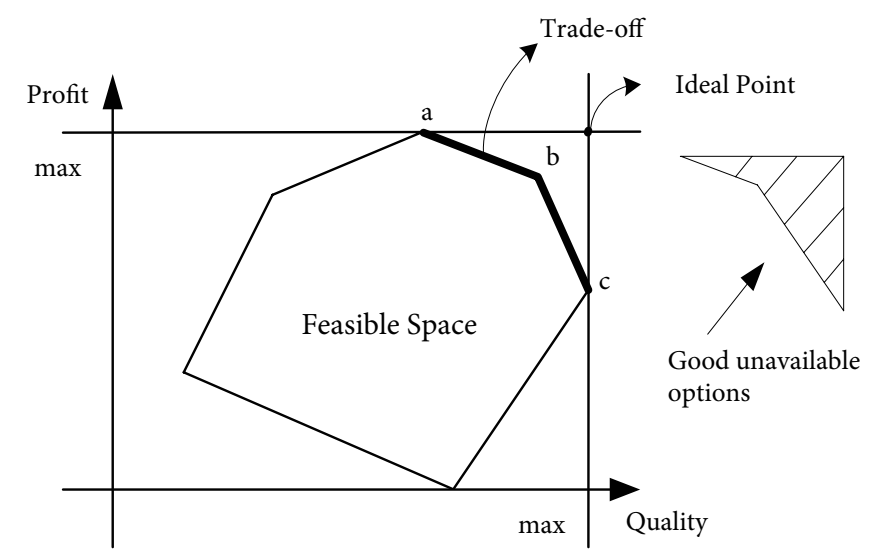

Fig. A2. Graphic example of De Novo programming 
- A simple production problem involving two products: suits and dresses in quantities $x_{1}$ and $x_{2}$, with each of them consuming five different resources (unit market prices of resources are given).

According to De Novo programming, the Maximum levels of two products can be calculated by mathematical programming:

Profit: $\max f_{1}\left(x_{1}, x_{2}\right)=400 x_{1}+300 x_{2}$

Quality: $\max f_{2}\left(x_{1}, x_{2}\right)=6 x_{1}+8 x_{2}$

$$
\begin{gathered}
\text { s.t. } 4 x_{1} \leq 20 \\
2 x_{1}+6 x_{2} \leq 24 \\
12 x_{1}+4 x_{2} \leq 60 \\
3 x_{2} \leq 10.5 \\
4 x_{1}+4 x_{2} \geq 26 \\
x_{1}, x_{2} \geq 0
\end{gathered} \Rightarrow\left[\begin{array}{cc}
4 & 0 \\
2 & 6 \\
12 & 4 \\
0 & 3 \\
4 & 4
\end{array}\right]\left[\begin{array}{l}
x_{1} \\
x_{2}
\end{array}\right] \leq\left[\begin{array}{c}
20 \\
24 \\
60 \\
10.5 \\
26
\end{array}\right],\left(\begin{array}{ll}
\text { s.t. } \quad \boldsymbol{A} \boldsymbol{x} \leq \boldsymbol{b} \\
x_{1}, x_{2} \geq 0
\end{array}\right)
$$

The data are summarized as follows:

\begin{tabular}{ccccc}
\hline $\begin{array}{c}\text { Unit price } \\
\$\end{array}$ & $\begin{array}{c}\text { Resources } \\
\text { (Raw material) }\end{array}$ & $\begin{array}{c}\text { Technological coefficients } \\
\text { (Resource Requirement) } \\
x_{1}\end{array}$ & $x_{2}$ & $\begin{array}{c}\text { No. of units } \\
\text { (Resource portfolio) }\end{array}$ \\
\hline 30 & Nylon & 4 & 0 & 20 \\
\hline 40 & Velvet & 2 & 6 & 24 \\
\hline 9.5 & Silver thread & 12 & 4 & 60 \\
\hline 20 & Silk & 0 & 3 & 26 \\
\hline 10 & Golden thread & 4 & 4 & 10.5 \\
\hline
\end{tabular}

- The costs of the given resources portfolio:

$(30 \times 20)+(40 \times 24)+(9.5 \times 60)+(20 \times 10.5)+(10 \times 26)=\$ 2600$

- Unit costs of producing one unit of each of the two products:

$$
\begin{aligned}
& x_{1}:(30 \times 4)+(40 \times 2)+(9.5 \times 12)+(20 \times 0)+(10 \times 4)=\$ 354 \\
& x_{2}:(30 \times 0)+(40 \times 6)+(9.5 \times 4)+(20 \times 3)+(10 \times 4)=\$ 378
\end{aligned}
$$

Ideal point as follows.

- Maximum $f_{1}\left(x_{1}, x_{2}\right)$ in profit:

$$
\begin{aligned}
f_{1}\left(x_{1}, x_{2}\right) \max & f_{1}\left(x_{1}, x_{2}\right)=400 x_{1}+300 x_{2} \\
\text { s.t. } & \boldsymbol{A} \boldsymbol{x} \leq \boldsymbol{b} \\
& x_{1}, x_{2} \geq 0
\end{aligned}
$$

Answer: $x_{1}=4.25, x_{2}=2.25 ; f_{1}^{*}=400 \times 4.25+300 \times 2.25=\$ 2375$ 
- Maximum $f_{2}\left(x_{1}, x_{2}\right)$ in total quality index $\max f_{2}\left(x_{1}, x_{2}\right)=6 x_{1}+8 x_{2}$

s.t. $\boldsymbol{A} \boldsymbol{x} \leq \boldsymbol{b}$

$$
x_{1}, x_{2} \geq 0
$$

Answer: $x_{1}=3.75, x_{2}=2.75 ; f_{2}^{*}=6 \times 3.75+8 \times 2.75=\$ 44.5$

Multi-objective programming:

$$
\begin{array}{ll}
\max & \left\{f_{1}(\boldsymbol{x}), \ldots, f_{i}(\boldsymbol{x}), \ldots, f_{k}(\boldsymbol{x})\right\} \\
\text { s.t. } & \boldsymbol{A} \boldsymbol{x} \leq \boldsymbol{b} \Rightarrow \begin{array}{ll}
\text { s.t. } & \boldsymbol{p}^{\prime} \boldsymbol{A} \boldsymbol{x} \leq \boldsymbol{p}^{\prime} \boldsymbol{b} \\
& \boldsymbol{x} \geq \mathbf{0} \geq \mathbf{0}
\end{array} \Rightarrow \begin{array}{ll}
\text { s.t. } & \boldsymbol{c}^{\prime} \boldsymbol{x} \leq \boldsymbol{B} \\
\boldsymbol{x} \geq \mathbf{0}
\end{array},
\end{array}
$$

where vector $\boldsymbol{p}$ denotes vector unit price of each resource; vector $\boldsymbol{c}^{\prime}=\boldsymbol{p}^{\prime} \boldsymbol{A}$ denotes "product unit cost", $\boldsymbol{B}$ denotes budget.

De Novo programming:

$\min c x$

$$
f_{i}(\boldsymbol{x}) \geq f_{i}^{*}, \quad i=1,2, \ldots, k
$$

$\boldsymbol{x} \geq \mathbf{0}$

Example:

$$
\begin{array}{ll}
\min & c x=354 x_{1}+378 x_{2} \\
\text { s.t. } & f_{1}\left(x_{1}, x_{2}\right)=400 x_{1}+300 x_{2} \geq 2375 \\
& f_{2}\left(x_{1}, x_{2}\right)=6 x_{1}+8 x_{2} \geq 44.5 \\
& x_{1}, x_{2} \geq 0
\end{array}
$$

\begin{tabular}{|c|c|c|c|c|}
\hline \multirow[t]{2}{*}{$\begin{array}{l}\text { Unit price } \\
\$\end{array}$} & \multirow[t]{2}{*}{$\begin{array}{c}\text { Resources } \\
\text { (Raw material) }\end{array}$} & \multicolumn{2}{|c|}{$\begin{array}{l}\text { Technological coefficients } \\
\text { (Resource Requirement) }\end{array}$} & \multirow{2}{*}{$\begin{array}{c}\text { No. of units } \\
\text { (Resource portfolio) } \\
\text { Original New design }\end{array}$} \\
\hline & & $x_{1}$ & $x_{2}$ & \\
\hline 30 & Nylon & 4 & 0 & $20>16.12$ \\
\hline 40 & Velvet & 2 & 6 & $24>23.3$ \\
\hline 9.5 & Silver thread & 12 & 4 & $60>58.52$ \\
\hline 20 & Silk & 0 & 3 & $10.5>7.62$ \\
\hline 10 & Golden thread & 4 & 4 & $26<26.28$ \\
\hline
\end{tabular}

- Maximum $f_{1}\left(x_{1}, x_{2}\right)$ in profit equal $\$ 2375$ :

Answer: $x_{1}=4.03, x_{2}=2.54 ; f_{1}^{*}=400 \times 4.03+300 \times 2.54=\$ 2375$

- Maximum $f_{2}\left(x_{1}, x_{2}\right)$ in total quality index:

Answer: $x_{1}=4.03, x_{2}=2.54 ; f_{2}^{*}=6 \times 4.03+8 \times 2.54=\$ 44.5$

- Cost of the newly designed system:

Answer: $(30 \times 16.12)+(40 \times 23.3)+(9.5 \times 58.52)+(20 \times 7.62)+(10 \times 26.28)=\$ 2386.74$

The data are summarized as follows: 
Toward a MCDM New Era - Professor Tzeng's Roadmap

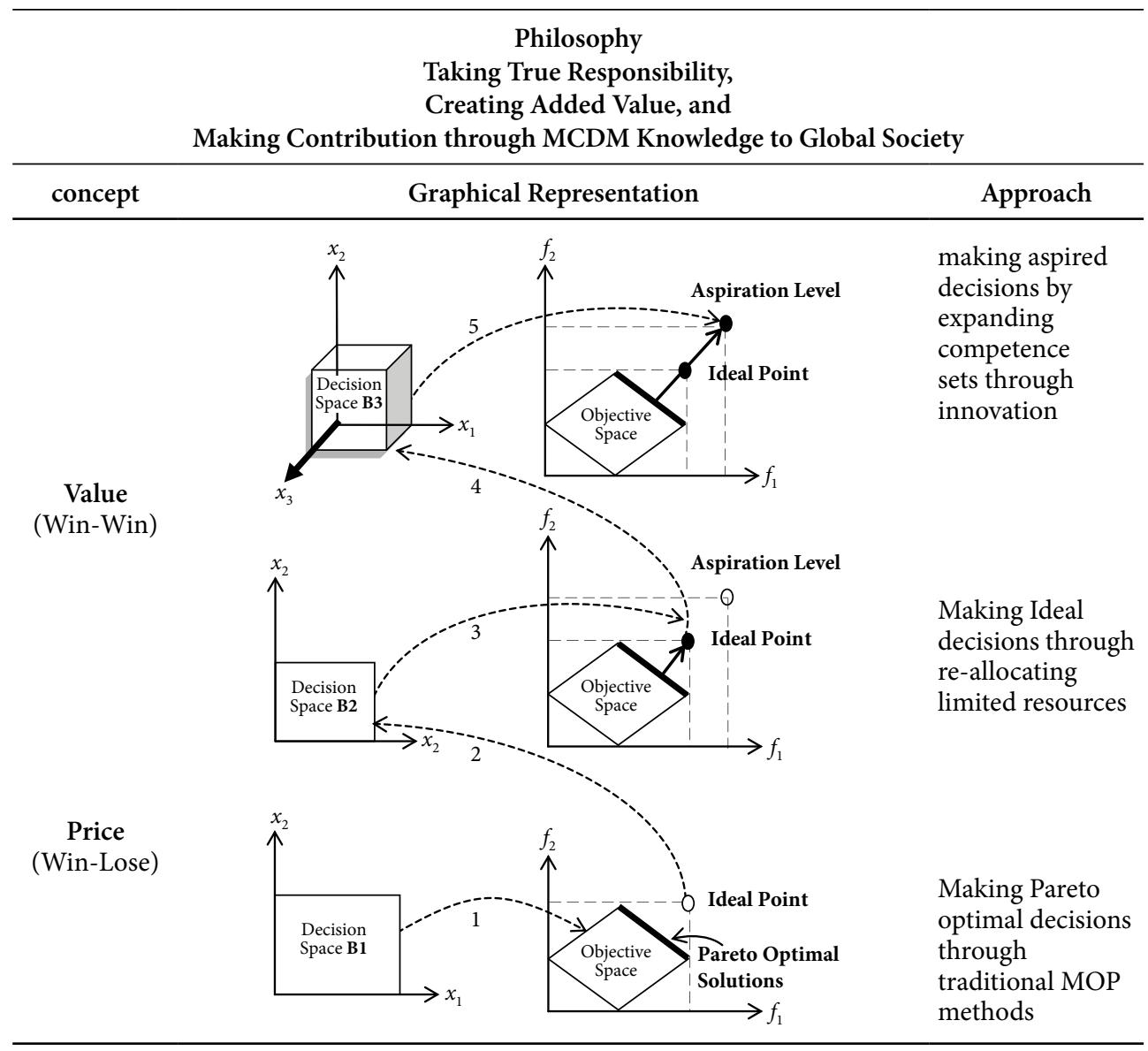

Fig. A3. Extension of changeable decision space and aspiration level

James J. H. LIOU received his Ph.D. degree from the Department of Mechanical and Aerospace Engineering of University of Missouri-Columbia, USA in 1996. After working for airline industry for 8 years, he became an assistant professor in the Department of Air Transportation at the Kainan University, Taiwan. He turned out to be an associate professor in 2008. Currently, he is an associate professor in the Department of Industrial Engineering and Management at National Taipei University of Technology. Dr Liou's primary research interest is data mining, including feature selection, clustering, ensemble methods, and decision support system. Recently, he became interested in applying data mining algorithms to solve some business problems in customer targeting, e-commerce, and safety science. He has publications in numerous journals, including Journal of Air Transport Management, Expert Systems with Applications, International Journal of Production Research, Applied Soft computing, Information Sciences and European Journal of Operational Research etc. 
Gwo-Hshiung TZENG was born in 1943 in Taiwan. In 1967, he received the Bachelor's degree in business management from the Tatung Institute of Technology (now Tatung University), Taiwan; in 1971, he received the Master's degree in urban planning from Chung Hsing University (Now Taipei University), Taiwan; and in 1977, he received the Ph.D. degree course in management science from Osaka University, Osaka, Japan.

He was an Associate Professor at Chiao Tung University, Taiwan, from 1977 to 1981, a Research Associate at Argonne National Laboratory from July 1981 to January 1982, a Visiting Professor in the Department of Civil Engineering at the University of Maryland, College Park, from August 1989 to August 1990, a Visiting Professor in the Department of Engineering and Economic System, Energy Modeling Forum at Stanford University, from August 1997 to August 1998, a professor at Chaio Tung University from 1981 to 2003, and a Chair Professor at Chiao Tung University. He got National Distinguished Chair Professor (Highest Honor offered by the Ministry of Education Affairs, Taiwan) and Distinguished Research Fellow (Highest Honor Offered by NSC, Taiwan) in 2000. His current research interests include statistics, multivariate analysis, network, routing and scheduling, multiple criteria decision making, fuzzy theory, hierarchical structure analysis for applying to technology management, energy, environment, transportation systems, transportation investment, logistics, location, urban planning, tourism, technology management, electronic commerce, global supply chain, etc. He has got a Highly Cited Paper (March 13, 2009) ESI "Compromise solution by MCDM methods: A comparative analysis of VIKOR and TOPSIS" published in the "European Journal of Operational Research" on July $16^{\text {th }}, 156(2), 445-455$, in 2004 it has been recently identified by Thomson Reuters' Essential Science Indicators ${ }^{S M}$ to be one of the most cited papers in the field of Economics.

He has got the MCDM Edgeworth-Pareto Award from the International Society on Multiple Criteria Decision Making (June 2009), has got the Pinnacle of Achievement Award 2005 of the world, and had got the National Distinguished Chair Professor and Award (highest honor offered) of the Ministry of Education Affairs of Taiwan and three times of distinguished research award and two times of distinguished research fellow (highest honor offered) of National Science Council of Taiwan. Fellow IEEE Member (from September 30, 2002). He organized a Taiwan affiliate chapter of the International Association of Energy Economics in 1984 and he was the Chairman of the Tenth international Conference on Multiple Criteria Decision Making, July 19-24, 1992, in Taipei; the Co-Chairman of the $36^{\text {th }}$ International Conference on Computers and Industrial Engineering, June 20-23, 2006, Taipei, Taiwan; the Chairman of the International Summer School on Multiple Criteria Decision Making 2006, July 2-14, Kainan University, Taiwan. He is a member of IEEE, IAEE, ISMCDM, World Transport, the Operations Research Society of Japan, the Society of Instrument and Control Engineers Society of Japan, the City Planning Institute of Japan, the Behaviormetric Society of Japan, the Japan Society for Fuzzy Theory and Systems; and participating many Society of Taiwan. He is editors-in-Chief of International Journal of Information Systems for Logistics and Management, and so on. 